\title{
A New Bursting Liability Evaluation Index for Coal -The Effective Elastic Strain Energy Release Rate
}

\author{
Zhiguo LU 1,2, * Wenjun JU 1,2 , Fuqiang GAO ${ }^{3}$, Youliang FENG ${ }^{1,2}$, Zhuoyue SUN 1,2, \\ Hao WANG ${ }^{4}$ and Kang YI ${ }^{1,5}$ \\ 1 Coal Mining and Designing Branch, China Coal Research Institute, Beijing 100013, China; \\ juwenjun@tdkcsj.com (W.J.); xinyangfyl@163.com (Y.F.); 18518745290@163.com (Z.S.); \\ kang-yi@outlook.com (K.Y.) \\ 2 Coal Mining and Designing Department, Tiandi Science and Technology Co Ltd, Beijing 100013, China \\ 3 National Key Laboratory of Coal Mining and Clean Utilization, China Coal Research Institute, \\ Beijing 100013, China; gaofuqiang@tdkcsj.com \\ 4 School of Energy Science and Engineering, Henan Polytechnic University, Jiaozuo 454000, China; \\ wanghao5393607@163.com \\ 5 School of Resource and Safety Engineering, China University of Mining and Technology (Beijing), \\ Beijing 100083, China \\ * Correspondence: cumtblzg@163.com; Tel.: +86-1352-050-5296
}

Received: 2 September 2019; Accepted: 26 September 2019; Published: 30 September 2019

\begin{abstract}
Because both faults and cleats exist in coal, sharp stress drops occur during loading when coal is deformed. These drops occur during the pre-peak stage and are accompanied by sudden energy releases. After a stress drop, the stress climbs slowly following a zigzag path and the energy accumulated during the pre-peak stage is unstable. A stress-strain curve is the basic tool used to evaluate the bursting liability of coal. Based on energy accumulation in an unsteady state, the pre-peak stress-strain curve is divided into three stages: pre-extreme, stress drop, and re-rising stage. The energy evolution of the specimen during each stage is analyzed. In this paper, an index called the effective elastic strain energy release rate (EESERR) index is proposed and used to evaluate the coal's bursting liability. The paper shows that the propagation and coalescence of cracks is accompanied by energy release. The stress climb following a zigzag path prolongs the plastic deformation stage. This causes a significant difference between the work done by a hydraulic press during a laboratory uniaxial compression experiment and the elastic strain energy stored in the specimen during the experiment, so the evaluation result of the burst energy index would be too high. The determination of bursting liability is a comprehensive evaluation of the elastic strain energy accumulated in coal that is released when the specimen is damaged. The index proposed in this paper fully integrates the energy evolution of coal samples being damaged by loading, the amount of elastic strain energy released during the sample failure divided by the failure time is the energy release rate. The calculation method is simplified so that the uniaxial compressive strength and elastic modulus are included which makes the new index more universal and comprehensive. Theoretical analysis and physical compression experiments validate the reliability of the evaluation.
\end{abstract}

Keywords: bursting liability; unstable energy accumulation; effective elastic strain energy; stress drop

\section{Introduction}

Safety and efficiency are two of the major goals in mining [1]. As coal mine production and mining depths in China increase, coal burst accidents are occurring more frequently. According to statistics, the number of coal mines susceptible to coal bursts in China has increased from 32 in 1985 to 177 in 2016. The dust produced by coal burst accidents seriously affects the working environment [2]. 
This seriously threatens efficient production and the safety of workers and mine infrastructure [1-5]. A considerable number of research projects on coal bursts have made significant progress on predicting the occurrence of coal bursts and numerous theories and prediction indexes have been proposed. These indexes include the Turchaninov index [6], Russenes index [7], Hoek index [8], and a brittleness index $\left(\sigma_{c} / \sigma_{t}\right)$ [2]. In addition, the technology for measuring coal burst precursors has also advanced including hardware and software for monitoring acoustic [9] and thermal infrared $[10,11]$ and for monitoring microseismicity [12,13].

Exploiting mineral resources, particularly when done by underground mining, causes stress redistribution and rock can fail suddenly when the imposed load exceeds the rock's ultimate bearing capacity. A coal burst (also called a rock burst, a coal bump, and other names) is a strong underground dynamic disaster caused by the sudden release of elastic strain energy from the surrounding rock [14-17]. Energy accumulations and their release are the important factors that must be studied to evaluate mine workings for coal burst liability and intensity. Conventional coal burst indexes based on energy theory include an energy release rate index [18], a burst energy index $\left(K_{E}\right)$ [19], an elastic energy index $\left(W_{E T}\right)$ [20], and the burst energy release index (BERI) [21]. Weng et al. [22] proposed a strain energy density index based on strain energy accumulations and their release. It was developed from numerical simulations in which the surrounding rocks with high strain energy density were suddenly damaged by the rapid release of that energy. This caused a coal burst. Brady et al. [23] and Jiang et al. [24] emphasized the influence of energy evolution in the pre-peak stage. The local energy release rate (LERR) was determined by calculating the differences between strain energies before and after brittle failure. $\mathrm{Xu}$ et al. [25] defined the ratio of the LERR to the limit energy storage rate (LESR) as the coal burst energy release rate based on energy evolution during coal failure. This was used as an index to evaluate bursting liability. Further analysis of the energy accumulation shows that more than half of the energy in the surrounding rock is stored as elastic strain energy. The energy is either dissipated during inelastic deformation, like shearing, or released instantaneously in the form of kinetic energy when the rock fractures. The sudden release of energy is what causes coal bursts [26]. Miao et al. [27] considered the accumulation of elastic strain energy to be the primary factor behind coal bursts and high stress to be the external cause for the accumulation and sudden release of elastic strain energy. Zhang et al. [28,29] pointed out that the elastic strain energy stored in the coal is the main source of the energy released during a coal burst. After a detailed analysis of energy transformation and the release of different forms of energy during coal burst, Yang et al. [30] proposed an elastic deformation energy release rate index that considered energy dynamic release time.

The instantaneous release of energy caused by the sudden failure of coal is the internal cause of coal bursts. Energy evolution is closely related to coal deformation and failure. Zheng [31] generated a mathematical model for dynamic deformation of rock and provided analytical solutions for different deformation modes. Zheng pointed out that rock failure is the result of energy transformation and dissipation in time and space. The shape of the stress-strain curves at the pre-peak and post-peak stages can reflect the stress and deformation state of rock; this is useful for understanding energy evolution [32,33]. Numerous uniaxial compression tests on coal samples show that stress drops in the pre-peak stage (which is equivalent to the energy suddenly released), demonstrating that the energy was in an unstable state at that stage. Based on these stress drops, this paper proposes a new energy index. This index, called the effective elastic strain energy release rate (EESERR) index, fully reflects the evolution of the energy in the coal samples during the sequence of events comprising loading, failure, and the dynamic release time of energy after failure. The index encapsulates the bursting liability of material caused by the release rate of elastic strain energy. The index's calculation method is simplified and the uniaxial compressive strength (UCS) and elastic modulus of the material are included. Theoretical and experimental verification show that this index is comprehensive and can be applied universally. 


\section{Materials and Methods}

\subsection{Uniaxial Compression Test}

Coal samples were collected from the No. 4 coal seam in the Tashan coal mine, Datong, Shanxi Province, China. All the coal specimens tested were cylinders $50 \mathrm{~mm}$ in diameter and $100 \mathrm{~mm}$ height. Uniaxial compression tests were conducted in the laboratory with a hydraulic press using displacement control and a loading rate of $10^{-5} \mathrm{~mm} / \mathrm{s}$. The test equipment is shown in Figure 1 . Displacements, loads, and other data were recorded and the samples' mechanical parameters such as peak strength and elastic modulus were obtained during the tests.

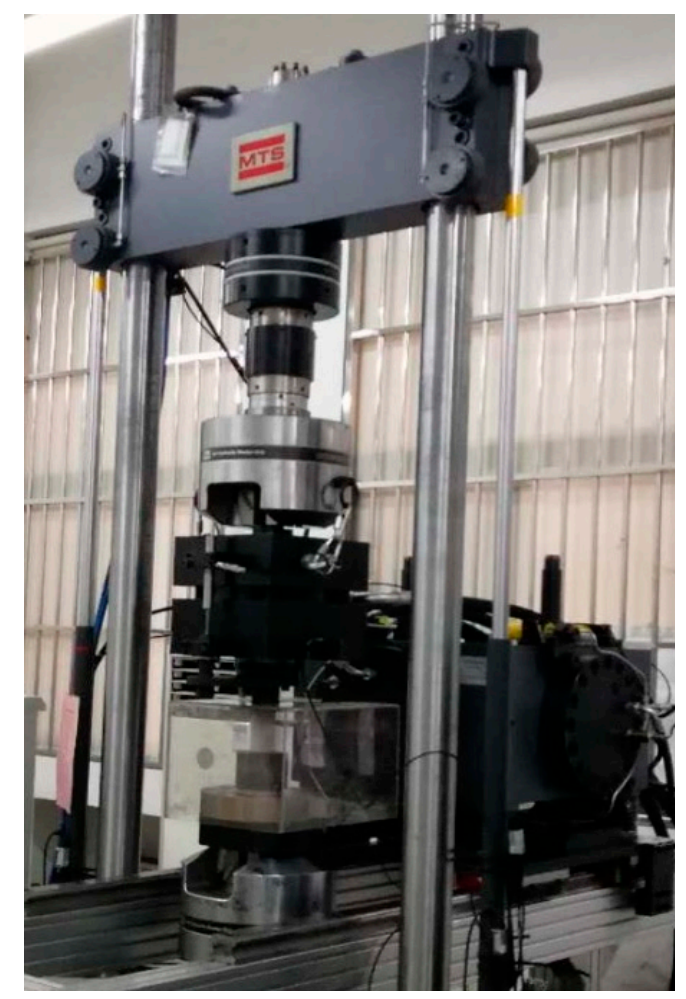

Figure 1. Test equipment.

\subsection{Pre-Peak Stress Drop and Bursting Liability}

Discontinuous, structurally weak planes are common in some heterogeneous materials including coal. Under external loads, the stress concentrations in these materials form at the ends of the structural planes and when fractures occur, they start where the original structure ends at a "rock bridge," the previously unbroken material between two weak structural planes. The new cracks and the original weak planes connect each other and this results in the local bearing capacity decreasing. When the discontinuous weak planes are approximately parallel, the new cracks grow in an orientation defined by the trends of the original weak planes, as shown in Figure 2. The new cracks connect with the original weak planes along the direction of maximum stress. There is a sudden stress drop when a new fracture breaks the rock bridge between two original weak planes. However, because the material has only been damaged locally, it still has a relatively high bearing capacity. Under load, the stress continues to rise. When new fractures occur and break other rock bridges, the stress-strain curve shows another sudden stress drop and as this process is repeated, the repeated internal failures lead to a zigzag climb of the pre-peak stress-strain curve. In this failure mode, the original weak planes and the new cracks cut the material into coherent structural blocks. Under load, both slip along the structural planes and rotation of the structural blocks occurs and results in intermittent deformation of specimens. When the specimen approaches final failure, slip along the structural planes becomes 
dominant and failure along these planes occurs in stages. Because this style of deformation is complex, its energy evolution needs to be analyzed in stages but it has rarely been studied in the way.

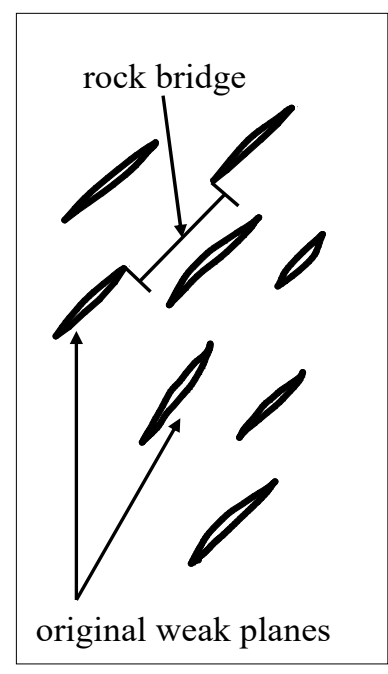

(a)

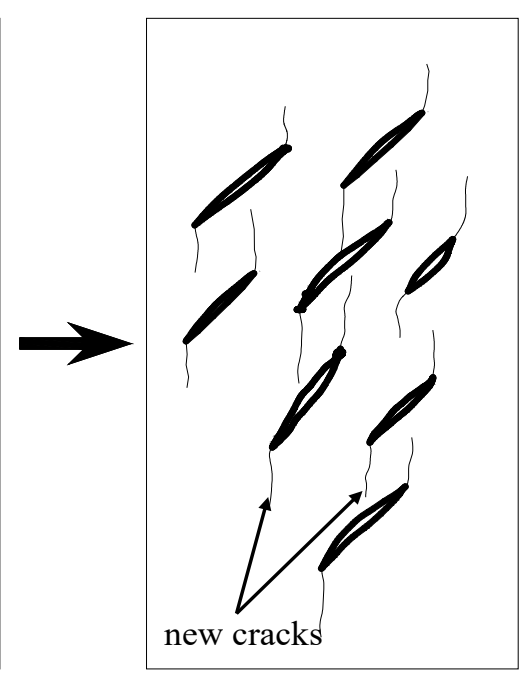

(b)

Figure 2. Sketch showing fracture development controlled by discontinuous weak planes under compressive stress. (a) Fracture distribution before loading; (b) Fracture distribution after loading.

When a rock bridge fractures and the fracture connects two weak planes, energy is released. However, according to conventional bursting liability indexes such as the $K_{E}$ [19], the specimen is in a steady state of energy accumulation in the pre-peak stage of the experiment except for inelastic deformation (in the compaction stage) which dissipate some energy [34]. Therefore, as shown by curve II in Figure 3, stress-strain curves for coal samples were analyzed comparatively. Curve II shows pre-peak stress drops associated with the formation of internal fractures in the sample. When calculating the accumulated strain energy before failure, the conventional bursting liability index does not take into account the energy released during the stress drops as rock bridges fracture at the pre-peak stage; this leads to a considerably higher bursting liability.

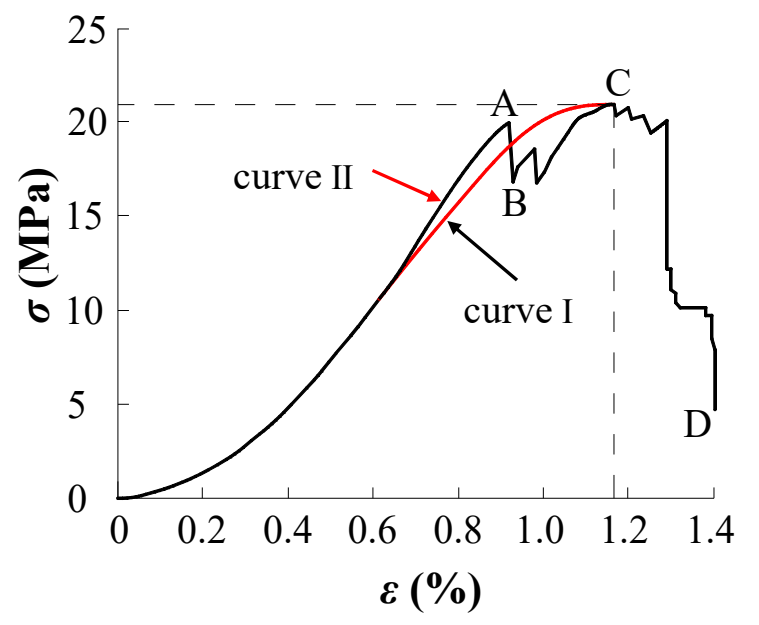

Figure 3. Comparative analysis of stress-strain curves for coal samples.

The two stress-strain curves in Figure 3 show that the UCSs of the coal samples are equal and the failure curves in the post-peak stage are identical. This means that the dynamic failure times $\left(D_{T}\right)$ are also equal and according to the conventional burst energy indexes, the strain energies accumulated in the pre-peak stages are also the same. Therefore, the two coal samples have the same bursting liability. 
However, curve II indicates that although the work done by the uniaxial press to generate curve II is the same as the work done to generate curve I, there is an obvious stress drop before curve II's peak and some elastic strain energy was released. The accumulated elastic strain energy in the curve II coal was significantly reduced, so its bursting liability should be lower. This shows that bursting liability values calculated from conventional indexes have some limitations when the stress climbs in a zigzag fashion, which is very common for coal samples with prominently weak structure. It is of important that a usable bursting liability index that considers the unsteady accumulation of energy in the pre-peak stage be available.

\subsection{Energy Evolution under Uniaxial Loading}

A coal burst occurs when, under external load, the elastic strain energy accumulated in the coal is suddenly released and coal debris is ejected outward at high speed. From the energy perspective [35], when the coal is loaded to its strength limit, only a small amount of energy input from an outside source, or, in some cases, only the energy accumulated in the coal, will destabilize the coal and cause a burst thus suddenly releasing the elastic strain energy accumulated in the coal. An accurate assessment of the amount of elastic strain energy accumulated is necessary to evaluate the coal's bursting liability. As described in the previous section, for coal with discontinuous weak structures, stress can rise along zigzag path in the pre-peak stage in a stress-strain curve and this represents unstable energy accumulations. For this paper, each zigzag vertex is defined as a stress extreme. This section explores the energy evolution of coal samples with stress extremes under uniaxial compression using stress-strain diagrams.

\subsubsection{Unstable Energy Accumulation in the Pre-Peak Stage}

Under uniaxial compression, some coal samples show multiple stress drops on a stress-strain curve in the pre-peak stage. However, the analysis in this section is simplified to consider only one stress drop on the curve and that single extreme point is shown as point A on Figure 4. The pre-peak stress-strain curve can be divided into three stages, the stage before the stress extreme, the pre-extreme stage (stage O-A on Figure 4), the stress drop stage (stage A-B), and the stage of the second stress increase, the stress re-rising stage (stage B-C). For coal samples that exhibit multiple stress drops, the A-B and B-C stages are repeated but the same method can be used to analyze those coals.

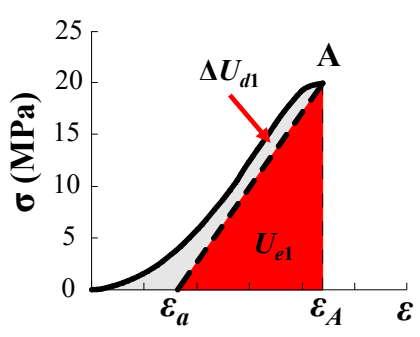

(a)

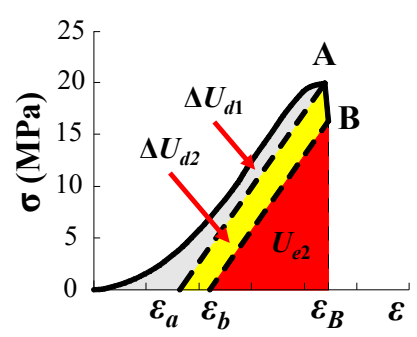

(b)

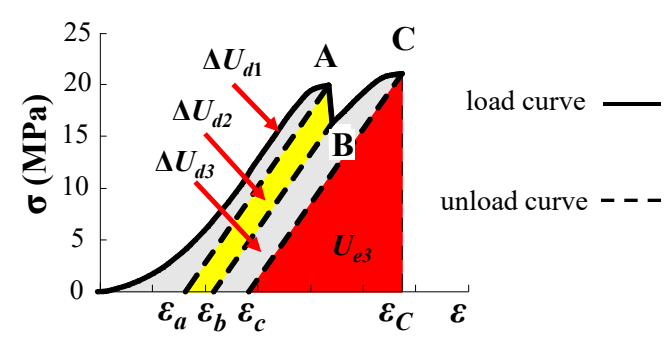

(c)

Figure 4. Illustrative graphs showing different energy states during pre-peak uniaxial compression: (a) pre-extreme stage (stage O-A); (b) stress drop stage (stage A-B); (c) stress re-rising stage (stage B-C).

Analyzing the pre-peak energy evolution is the basis for determining the state of the elastic strain energy before sample failure. Ignoring heat exchange, the work done by external forces and the energy change in the specimen are equal, namely $W=U$, where $W$ is the amount of work done by the external forces and $U$ is the value of energy change in the specimen. In a uniaxial compression test, $W$ is the mechanical work done by the hydraulic press.

Before the first stress extreme on the stress-strain curve, the coal sample goes through three stages, a compaction stage, an elastic deformation stage, and a plastic deformation stage. In the elastic deformation stage, the work done by the hydraulic press is mainly stored in the specimen as elastic 
strain energy. In the compaction stage and the plastic deformation stage, a portion of the energy is dissipated by inelastic deformation, that is,

$$
W_{1}=U_{e 1}+\Delta U_{d 1}
$$

where $W_{1}$ is the mechanical work done by the hydraulic press on the coal sample in the pre-extreme stage, $U_{e 1}$ is elastic strain energy accumulated in the specimen in the pre-extreme stage, $\Delta U_{d 1}$ is the increment of energy dissipated in the pre-extreme stage.

Calculating the elastic strain energy accumulated and dissipated quantitatively is fundamental for assessing bursting liability. When the load on the coal sample reaches stress extreme point $\mathrm{A}$, unloading will follow a new unloading curve instead of returning along the original curve, as shown in Figure 4a. Mechanical work done by the hydraulic press can be calculated from Equation (2):

$$
W_{1}=V \int_{O}^{\varepsilon_{A}} \sigma \mathrm{d} \varepsilon
$$

where $V$ is the volume of the coal sample, $O$ is the origin of stress-strain curve, $\varepsilon_{A}$ is the corresponding strain at extreme point $\mathrm{A}, \sigma$ is the stress-strain curve under loading.

It should be pointed out that the unloading curve is obtained by assuming that unloading occurs at a given time, and the following should be the same. The increment of elastic strain energy accumulated in the specimen before the stress extreme can be determined by solving Equation (3):

$$
U_{e 1}=V \int_{\varepsilon_{a}}^{\varepsilon_{A}} \sigma_{d 1} \mathrm{~d} \varepsilon
$$

where $\varepsilon_{a}$ is the strain recovery point on the unloading curve when the stress reaches the extreme, $\sigma_{d 1}$ is the stress-strain curve during unloading. Combining Equations (1)-(3) yields an equation for the increment of energy dissipation, Equation (4):

$$
\Delta U_{d 1}=V \int_{O}^{\varepsilon_{A}} \sigma \mathrm{d} \varepsilon-V \int_{\varepsilon_{a}}^{\varepsilon_{A}} \sigma_{d} \mathrm{~d} \varepsilon .
$$

Under continuous loading, because the rock bridges fracture and the new cracks connect the weak planes, the stress-strain curve enters the stress drop stage. The energy is released suddenly when the rock bridges fracture and the weak planes are connected.

As shown in Figure $4 \mathrm{~b}$, the stress drops abruptly to $\sigma_{B}$ and the strain becomes $\varepsilon_{B}$. The work done by the hydraulic press at stress drop stage $W_{2}$ can be calculate from Equation (5):

$$
W_{2}=V \int_{\varepsilon_{A}}^{\varepsilon_{B}} \sigma \mathrm{d} \varepsilon
$$

At the moment unloading curve $\sigma_{d 2}$ is formed, the increment of energy dissipation during the stress drop stage can be represented by the area with the points $A-B-\varepsilon_{b}-\varepsilon_{a}$ as vertices (Figure $4 b$ ). The energy dissipated is mainly transformed into surface energy [35] that is used to form new structures in the coal like rock bridge fractures or to propagation existing cracks. The energy transformations can be represented by Equations (6) and (7):

$$
\begin{gathered}
\Delta U_{d 2}=W_{1}+W_{2}-\Delta U_{d 1}-U_{e 2}, \\
U_{e 2}=V \int_{\varepsilon_{b}}^{\varepsilon_{B}} \sigma_{d 2} \mathrm{~d} \varepsilon,
\end{gathered}
$$

where $U_{e 2}$ is elastic strain energy accumulated in the coal sample after the stress drop, $\varepsilon_{b}$ is the strain recovery point on the unloading curve at stress drop point B (Figure $4 b$ ). 
As shown in Figure 4c, after the rock bridge fractures and the new cracks connect the weak planes, the bearing capacity of the coal sample does not fall to zero. Under the continuous load, the stress-strain curve enters the stress re-rising stage until the stress peak. The work done by the press in this re-rising stage can be expressed as

$$
W_{3}=V \int_{\varepsilon_{B}}^{\varepsilon_{C}} \sigma \mathrm{d} \varepsilon
$$

where $\varepsilon_{C}$ is the peak strain.

When the stress reaches its peak, unloading takes place forming curve $\sigma_{d 3}$ on the stress-strain graph with strain recovery point $\varepsilon_{c}$. The increment of energy dissipation can be calculated from Equations (9) and (10):

$$
\begin{gathered}
\Delta U_{d 3}=W_{1}+W_{2}+W_{3}-\Delta U_{d 1}-\Delta U_{d 2}-U_{e 3} \\
=V \int_{\varepsilon_{O}}^{\varepsilon_{C}} \sigma \mathrm{d} \varepsilon-\Delta U_{d 1}-\Delta U_{d 2}-U_{e 3} \\
U_{e 3}=V \int_{\varepsilon_{\mathrm{c}}}^{\varepsilon_{C}} \sigma_{d 3} \mathrm{~d} \varepsilon,
\end{gathered}
$$

where $U_{e 3}$ is the elastic strain energy accumulated in the coal sample after the stress drop.

\subsubsection{Post-peak Energy Release}

When the external load exceeds the coal sample's strength, the stress-strain curve enters the post-peak failure stage. Analyzed from the energy point of view, the specimen is generally in a state of energy release in this stage as shown in Figure 5.

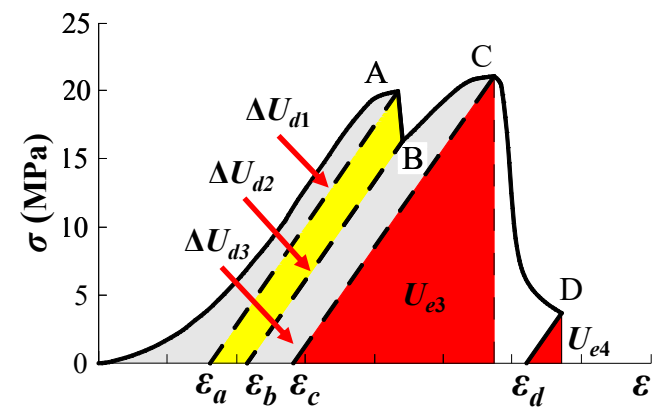

(a)

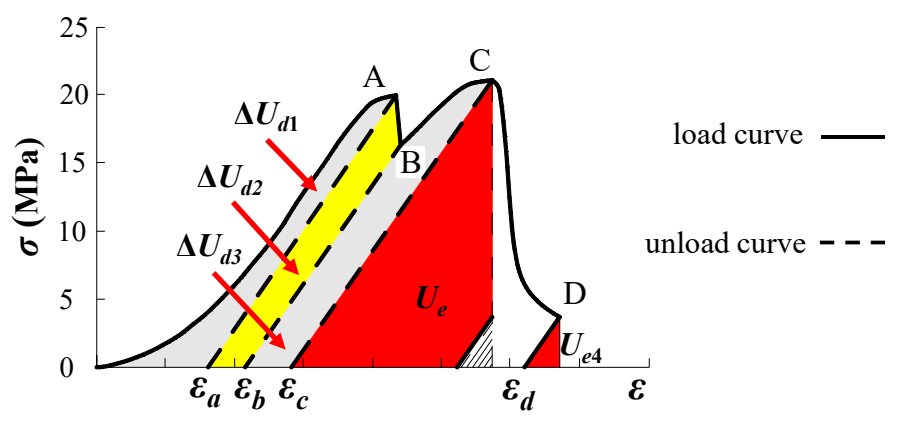

(b)

Figure 5. Illustrative graphs showing post-peak energy revolution under uniaxial compression. (a) residual elastic strain energy in the specimen when the stress drops to the residual strength, namely and (b) the releasable elastic strain energy in the post-peak stage.

In this stage, the negative work done by the hydraulic press is dissipated when the specimen fails. For a coal sample with strong bursting liability, the elastic strain energy accumulated in the pre-peak stage is transformed into kinetic energy that is instantaneously released in this stage and the stress immediately drops to its residual strength. The specimen's residual strength is $\sigma_{D}$, the corresponding strain is $\varepsilon_{D}$, and the work done by the hydraulic press in the post-peak stage, $\mathrm{W}_{4}$, can be represented by Equation (11):

$$
W_{4}=V \int_{\varepsilon_{C}}^{\varepsilon_{D}} \sigma \mathrm{d} \varepsilon
$$


When the stress reaches its residual strength, unloading takes place forming curve $\sigma_{d 4}$ on the stress-strain graph with strain recovery point $\varepsilon_{d}$ (Figure 5a). The increment of energy dissipation can be calculated from Equation (12):

$$
\begin{aligned}
\Delta U_{d 4} & =W_{1}+W_{2}+W_{3}+W_{4}-\Delta U_{d 1}-\Delta U_{d 2}-\Delta U_{d 3}-U_{e 4} \\
& =\int_{\varepsilon_{O}}^{\varepsilon_{D}} \sigma \mathrm{d} \varepsilon-\Delta U_{d 1}-\Delta U_{d 2}-\Delta U_{d 3}-U_{e 4}
\end{aligned}
$$

where $U_{e 4}$ is residual elastic strain energy in the specimen when the stress drops to the residual strength, namely,

$$
U_{e 4}=V \int_{\varepsilon_{d}}^{\varepsilon_{D}} \sigma_{d 4} \mathrm{~d} \varepsilon
$$

If the specimen loses its bearing capacity completely after failure, the residual strength is $0 \mathrm{MPa}$, so $\sigma_{D}=0$ and thus $U_{e 4}=0$.

From Equations (10) and (13), the releasable elastic strain energy in the post-peak stage is the difference between the elastic strain energy accumulated in the coal sample after the stress drop and the residual elastic strain energy, or

$$
\begin{aligned}
\Delta U_{e} & =U_{e 3}-U_{e 4} \\
& =V \int_{\varepsilon_{\mathcal{c}}}^{\varepsilon_{C}} \sigma_{d 3} \mathrm{~d} \varepsilon-V \int_{\varepsilon_{d}}^{\varepsilon_{D}} \sigma_{d 4} \mathrm{~d} \varepsilon
\end{aligned}
$$

\section{Results-The EESERR Index}

\subsection{A Bursting Liability Index Based on Energy Evolution}

Coal burst are caused by the sudden release of elastic strain energy stored in the surrounding rock of roadways and stopes. Bursting liability is the comprehensive numerical expression of mechanical parameters during the coal sample is destroyed and the elastic strain energy released, when the external load exceeds the coal's bearing capacity. The bursting liability index is a value that represents the release rate of a coal sample's accumulated elastic strain energy when it is fractured under a load [36].

When a coal burst occurs, the sudden release of elastic strain energy results in the ejection of coal debris. Therefore, the amount of stored elastic strain energy and the rate at which it is released are the most important factors that contribute to bursting liability. The EESERR index is calculated from the amount of elastic strain energy released and $D_{T}$. It is the amount of elastic strain energy released per unit time when the coal sample is destroyed or the rate at which the elastic strain energy is transformed into kinetic energy. It represents the failure bursting capacity of the specimen. It can be seen that the greater the EESERR index is, the higher the bursting capacity. The EESERR index can be calculated from Equation (15):

$$
\operatorname{EESERR}=\frac{\Delta U_{e}}{D_{T}}
$$

where $D_{T}$ is dynamic failure time for the specimen, which refers to the time from peak strength to residual strength of the specimen.

Combined with Equation (14), the equation for EESERR can be rewritten as

$$
E E S E R R=\frac{V \int_{\varepsilon_{\mathcal{C}}}^{\varepsilon_{C}} \sigma_{b 3} \mathrm{~d} \varepsilon-V \int_{\varepsilon_{d}}^{\varepsilon_{D}} \sigma_{b 4} \mathrm{~d} \varepsilon}{D_{T}}
$$

\subsection{Index Validation}

The stress-strain curves for coal samples with pre-peak stress-drops and a certain amount of residual strength in the post-peak stage (O-A-B-C-D, $D \neq 0$ ) are degenerated twice. These degenerations can be divided into a pre-peak non-stress drop (O-C-D, $\mathrm{D} \neq 0$ ) and post-peak non-residual strength 
(O-C-D, $\mathrm{D}=0$ ), as shown in Figure 6. Illustrative graphs showing EESERR can be applied to stress-strain curves for coal samples with and without pre-peak stress drops and residual strength.

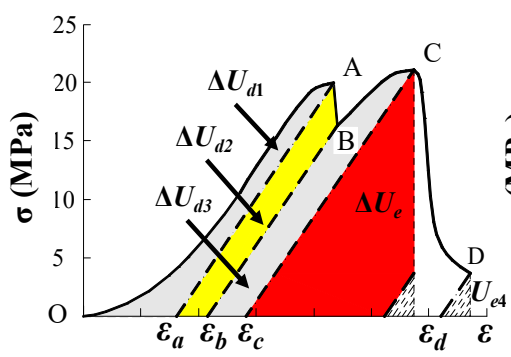

(a)

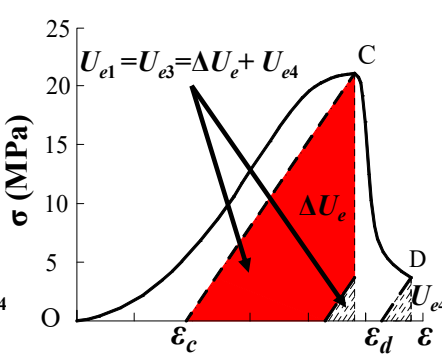

(b)

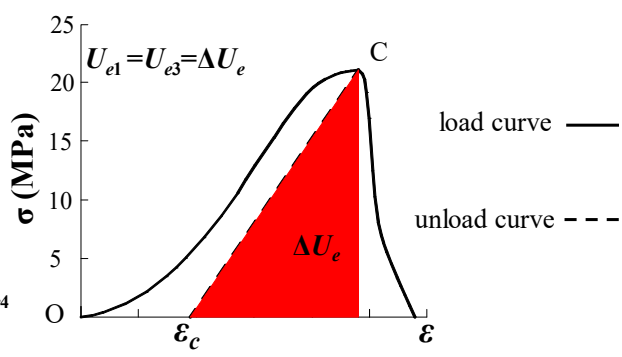

(c)

Figure 6. Degeneration of effective elastic strain energy rate index. (a) the stress-strain curves for coal samples with pre-peak stress-drops and a certain amount of residual strength in the post-peak stage; (b) the stress-strain curves for coal samples with pre-peak non-stress drop and (c) the stress-strain curves for coal samples with post-peak non-residual strength.

From Figure $6 \mathrm{a}, \mathrm{b}$, the energy evolution in the pre-peak stage after degeneration is exactly the same as the pre-extreme stage. As the load continues to increase, the stress-strain curve enters the post-peak stage, that is, the stress drop stage and the stress re-rising stage do not take place and the elastic strain energies are equivalent:

$$
U_{e 3}=U_{e 1}
$$

The elastic strain energy accumulated in the specimen in the pre-peak stage is the same as the conventional curve. In this case, EESERR can be calculated from Equation (18):

$$
\text { EESERR }=\frac{\Delta U_{e}}{D_{T}}=\frac{U_{e 1}-U_{e 4}}{D_{T}}=\frac{V \int_{\varepsilon_{c}}^{\varepsilon_{C}} \sigma_{d 3} \mathrm{~d} \varepsilon-V \int_{\varepsilon_{d}}^{\varepsilon_{D}} \sigma_{d 4} \mathrm{~d} \varepsilon}{D_{T}} .
$$

As shown from Figure $6 \mathrm{~b}, \mathrm{c}$, the specimen completely loses its bearing capacity in the post-peak stage and has no residual strength, $U_{e 4}=0$. In this case, EESERR can be calculated from Equation (19):

$$
\text { EESERR }=\frac{\Delta U_{e}}{D_{T}}=\frac{U_{e 1}-0}{D_{T}}=\frac{V \int_{\varepsilon_{a}}^{\varepsilon_{A}} \sigma_{3} \mathrm{~d} \varepsilon}{D_{T}} .
$$

After the degeneration of the EESERR index, the calculation method uses the concept that the elastic strain energy release rate determines the coal's bursting liability [36]. It shows that the EESERR index fully considers the all possibilities of energy accumulation and release during loading and deformation of coal on the basis of previous studies and validates the correctness of its theoretical derivation. That is, the conventional bursting liability index calculation is based on the simplified stress-strain curve (Figure 6c). This new EESRR index is derived from the more accurate stress-strain curve, not the simplified curve.

\subsection{Index Simplification}

Section 3.2 shows that although the EESERR index is universal and it is calculated in the same way the conventional indexes are calculated, there are several technical difficulties in accurately measuring the energy accumulation and release for each stage. Under cyclic loading-unloading, the unloading point selected has a significant effect on the energy accumulation and release calculation for each stage, but before the specimen fails, it is impossible to obtain the sample's diagnostic points. Therefore, the procedure for calculating the EESERR index is simplified so that it can be used under conventional uniaxial compression conditions. 
During sample compression, irrecoverable deformation occurs in both the compaction stage and the plastic deformation stage, so the strain recovery point of unloading curve $\sigma_{d}$ is to the right of the origin. During cyclic loading-unloading tests, the cyclic loading and unloading curves show that the specimen's elastic modulus decreases as loading progresses [37]. The elastic modulus Ed determined from the unloading curve is related to the damage variable calculated for crack development and propagation. The elastic modulus of damaged rock can be expressed as

$$
E_{d}=(1-D) E,
$$

where $E_{d}$ is the elastic modulus of the damaged rock, that is the elastic modulus from the unloading curve. The variable $D$ is the damage variable ( $D$ increases as loading progresses) and $E$ is the corresponding elastic modulus from the loading curve [17,38].

Given the low degree of specimens damage after the first loading, $D=0$ [35] so

$$
E_{d}=E_{A}=E_{B}=E_{C}=E_{D}=E
$$

In this case, the elastic strain energy stored in the specimen at peak stress and the residual strength can be simplified to $\frac{\sigma_{C}^{2}}{2 E}$ and $\frac{\sigma_{D}^{2}}{2 E}$, respectively. Then the EESERR index can be simplified to

$$
\text { EESERR }=\frac{\frac{\sigma_{C}^{2}}{2 E}-\frac{\sigma_{D}{ }^{2}}{2 E}}{D_{T}}=\frac{\sigma_{C}^{2}-\sigma_{D}^{2}}{2 E D_{T}} .
$$

The bursting liability index is based on energy evolution and takes unstable energy accumulations in the pre-peak stage into account. It is a well-established index. Unlike other indexes, the EESERR index fully considers the energy releases caused by rock bridges being fractured and it also considers the energy contributions from weak structural planes in the coal in the plastic deformation stage. This new index can be applied more universally.

As demonstrated by Equation (22), the EESERR index is defined by the difference between peak strength and residual strength, the elastic modulus, and $D_{T}$. Based on existing bursting liability indexes, such as UCS and $D_{T}$, threshold values for bursting liability evaluated by the EESERR index are shown in Table 1.

Table 1. Threshold values for bursting liability as determine by the effective elastic strain energy release rate (EESERR) index.

\begin{tabular}{cccc}
\hline Category & No Bursting Liability & Weak Bursting Liability & Strong Bursting Liability \\
\hline UCS $(\mathrm{MPa})$ & $<7$ & $7 \leq \mathrm{UCS}<14$ & $\geq 14$ \\
$D_{T}(\mathrm{~ms})$ & $>500$ & $50<\mathrm{D}_{\mathrm{T}} \leq 500$ & $\leq 50$ \\
EESERR & $<0.0163$ & $0.0163 \leq B_{v}<0.653$ & $\geq 0.653$ \\
\hline
\end{tabular}

\subsection{Index Application}

Displacements, loads, and other data were recorded and the samples' mechanical parameters such as peak strength and elastic modulus were obtained during the uniaxial compression tests. The failure modes and stress-strain curves of the five coal samples tested are shown in Figure 7. The bursting liability indexes were calculated and compared on the basis of these data. The results are shown in Table 2. 


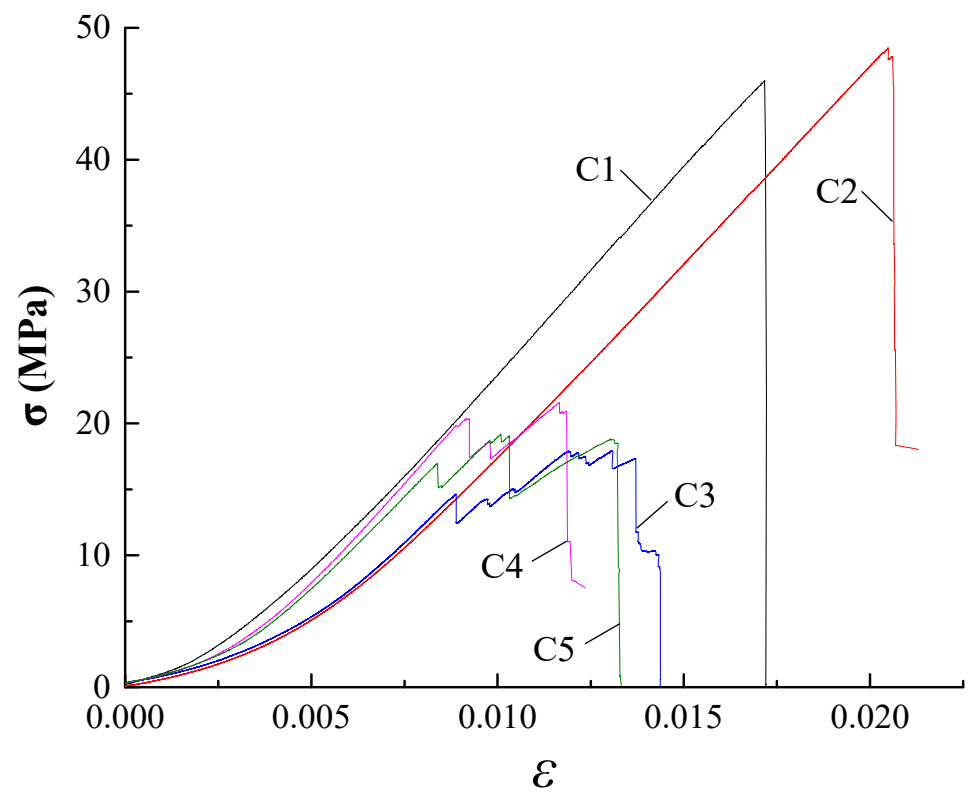

Figure 7. Uniaxial compression stress-strain curves and failure modes of five samples from the Tashan coal mine, Shanxi Province, China.

As is shown in Figure 7, the stresses on samples C1 and C2 increased uniformly with the load in the pre-peak stage and there was no stress drop. After peak stress, sample $\mathrm{C} 1$ completely lost all its bearing capacity but sample $\mathrm{C} 2$ had a residual strength of $18.339 \mathrm{MPa}$. There were obvious stress drops for samples C3, C4, and C5 after they entered the plastic deformation stage and their stress-strain curves climb slowly in a zigzag path under the continuously increasing load. Samples C3 and C5 failed completely but sample C4 retained a residual strength of 7.533 MPa.

Table 2. Mechanical parameters and bursting liability indexes for coal samples from the Tashan coal mine, Shanxi Province, tested under uniaxial compression.

\begin{tabular}{|c|c|c|c|c|c|c|c|c|c|c|c|c|}
\hline & $\begin{array}{c}E \\
(\mathrm{GPa})\end{array}$ & $\begin{array}{c}\text { UCS } \\
\text { (MPa) }\end{array}$ & $\begin{array}{c}R_{S} \\
(\mathrm{MPa})\end{array}$ & $\begin{array}{c}W_{P} \\
\left(\mathrm{~J} \cdot \mathrm{m}^{-3}\right)\end{array}$ & $\begin{array}{c}W_{P E} \\
\left(\mathrm{~J} \cdot \mathrm{m}^{-3}\right)\end{array}$ & $\begin{array}{c}W_{R E} \\
\left(\mathrm{~J} \cdot \mathrm{m}^{-3}\right)\end{array}$ & $W_{E T}$ & $K_{E}$ & $\begin{array}{c}D_{T} \\
\text { (ms) }\end{array}$ & $\begin{array}{c}W_{T} \\
\left(\mathrm{~s}^{-1}\right)\end{array}$ & EESERR & $\begin{array}{c}\text { Bursting } \\
\text { Liability } \\
\text { Evaluation }\end{array}$ \\
\hline $\mathrm{C} 1$ & 3.147 & 45.998 & 0 & 0.4732 & 0.3361 & 0 & 2.453 & 23.670 & 16.303 & 1451.927 & 20.618 & strong \\
\hline C3 & 2.448 & 17.903 & 0 & 0.1258 & 0.0604 & 0 & 0.925 & 6.992 & 519.906 & 13.448 & 0.116 & weak \\
\hline $\mathrm{C} 4$ & 2.931 & 21.585 & 7.533 & 0.1553 & 0.0795 & 0.0097 & 1.049 & 19.918 & 226.625 & 87.891 & 0.308 & weak \\
\hline C5 & 2.754 & 18.811 & 0 & 0.1765 & 0.0642 & 0 & 0.572 & 30.495 & 136.191 & 223.915 & 0.472 & weak \\
\hline
\end{tabular}

Note: Where $E$ is the elastic modulus (also called young's modulus), UCS is uniaxial compressive strength, $R_{S}$ is residual strength, $W_{P}$ is strain energy in the pre-peak stage, $W_{P E}$ is elastic strain energy in the pre-peak stage, $W_{R E}$ is residual elastic strain energy, $W_{E T}$ is elastic energy index, $D_{T}$ is dynamic failure time, $W_{T}$ is bursting energy rate index [36], EESERR is the effective elastic strain energy release rate index.

When the existing bursting liability indexes are compared, it is clear that the different indexes reach very different conclusions about the bursting liability of the same coal sample. According to the UCS and the $K_{E}$, all the coal samples listed in Table 2 have a strong bursting liability. According to the $W_{T}, \mathrm{C} 1, \mathrm{C} 2$, and $\mathrm{C} 5$ have strong bursting liabilities whereas $\mathrm{C} 3$ and $\mathrm{C} 4$ have weak liabilities. According to $D_{T}, C 1$ and $C 2$ have strong liability, the bursting liabilities of $C 4$ and $C 5$ are weak, and $C 3$ has non-bursting liability. According to $W_{E T}, \mathrm{C} 2$ has a strong bursting liability, $\mathrm{C1}^{\prime}$ s bursting liability is weak, and C3, C4, and C5 are non-bursting.

The EESERR index was used to evaluate the bursting liability of the five coal samples listed in Table 2. The results showed that $\mathrm{C} 1$ and $\mathrm{C} 2$ had strong bursting liabilities, whereas $\mathrm{C} 3, \mathrm{C} 4$, and $\mathrm{C} 5$ had weak bursting liabilities. Judging from the evaluation results, the new index combines many 
of the parameters considered by the existing bursting liability indexes, so it is more well-grounded. Coal is a material with prominent structures so there is a stage of pore and crack compaction in the initial loading stage. This stage is dominated by plastic deformation so specimens accumulate little elastic strain energy. After the specimens enter the elastic deformation stage, stress-strain curves rise approximately linearly when specimens are under a continuous load. This stage is the main stage of elastic deformation energy accumulation. After the specimens enter the plastic deformation stage, they are damaged in stages by slip along structural planes and rotation of the structural blocks, the stress-strain curve shows a sudden drop before it continues to rise in a zigzag fashion. The sudden stress drop indicates that the coal sample's internal structure is weakened and this is accompanied by the release of energy; the accumulation of elastic strain energy decreases. These deformations result in the plastic deformation stage being prolonged and this is reflected in the multiple stress drops and the slow zigzag climb of the stress-strain curve. In this stage, the inelastic deformation causes the energy dissipation to increase and thus the bursting liability decreases.

The existing bursting indexes each reflect only a single aspect of the bursting liability, so their predictive capabilities are limited. UCS reflects the energy accumulation capacity of the specimen to some extent, but UCS is not necessarily related to bursting liability. The work done by the hydraulic press in the pre-peak stage of a compression test is not all stored in the specimen in the form of elastic strain energy. The $K_{E}$ is calculated by ratio of pre-peak to post-peak stage energy but the elastic strain energy stored during the pre-peak stage is not independently analyzed so the bursting liability values calculated by this index are commonly too high. The $W_{E}$ and $D_{T}$ consider elastic strain energy storage and release time as factors affecting bursting liability, but those two aspects are not considered together. Thus both those approaches still have limitations.

A bursting liability index should be a comprehensive evaluation of the coal's mechanical properties. The EESERR index proposed in this paper is based on the unstable accumulation of elastic strain energy in the pre-peak stage. This new index takes the accumulation of elastic strain energy before failure and the residual elastic strain energy post-failure into account to calculate the release of elastic strain energy during failure. The release rate of the elastic strain energy is the amount of energy released divided by the failure time. This released rate of elastic strain energy is used to determine the bursting failure capacity of the specimen. To simplify the calculation, the UCS and elastic modulus are included in the calculation and thus the mechanical parameters related to coal bursting damage are all considered so that the evaluation will be more comprehensive and accurate.

Comparing the work done by the hydraulic press with the pre-peak elastic strain energy accumulated during the uniaxial compression test found that there was a significant difference between the two. When a stress drop occurs in the pre-peak stage but the stress then slowly climbs along a zigzag path, energy from inelastic deformation and internal structural damage is dissipated. This means that the accumulated elastic strain energy is reduced and it is then less than the work done by the hydraulic press to compress the sample. In this case, the evaluation of bursting liability produced by the conventional bursting energy indexes will be too high. The EESERR index proposed in this paper can analyze the elastic strain energy accumulated in the specimen during the pre-peak stage independently and make a more accurate bursting liability evaluation.

\section{Conclusions}

The determination of bursting liability is a comprehensive evaluation of the mechanical properties during the failure of coal and elastic strain energy released. Analysis of stress-strain curves from coal samples under load finds that stress drops in the pre-peak stage are very common. An index to evaluate the bursting liability of coal called the EESERR index is proposed. This paper presents theoretical verification for this index and the results of test that demonstrate its practical application. The main conclusions reached by this study are as follows:

(1) For coals with prominent structures, both slip along structural planes and rotation of the structural blocks cause coal samples to undergo intermittent failure during uniaxial compression tests. 
The stress-strain curve from these tests show sudden drops in the pre-peak stage and these stress drops are accompanied by energy release. After these stress drops, the stress' slow climb following a zigzag path prolongs the samples' plastic deformation stage. The elastic strain energy accumulated in the coal sample is decreased by the stress drops in the pre-peak stage, so the, bursting liability of the specimen is lowered. However, the conventional burst energy indexes do not account for this lower level of accumulated elastic strain energy in the pre-peak stage. Therefore, the results from the conventional burst energy indexes are too high when these indexes are applied to material with prominent structures, like coal.

(2) A new bursting liability index called the EESERR index is proposed in this paper. It is based on the unstable accumulation of elastic strain energy in the pre-peak stage and the time required to release that energy (the dynamic release time) after failure. The index fully integrates the coal sample's energy evolution in each stage of loading and failure and accounts for the accumulated, transformed, and the residual elastic strain energy in the whole process. The amount of elastic strain energy released by sample divided by the failure time yields the elastic strain energy release rate, and the bursting liability is determined by this energy release rate.

(3) The accurate calculation of the energy accumulated and released at each stage is the key to evaluating the bursting liability. When cyclic loading-unloading experiments are carried out, it is impossible to capture each unloading point accurately before the coal sample fails. Therefore, it was necessary to simplify the EESERR index calculation. The energy accumulated and released in each stage can be obtained from the uniaxial compression test and the UCS and elastic modulus can be included in the simplified calculation. The new index takes the diverse mechanical parameters related to coal's bursting failure into account.

Author Contributions: Conceptualization, Z.L. and W.J.; methodology, Z.L. and F.G.; software, Z.L. and K.Y.; validation, Z.L.; formal analysis, Z.L.; investigation, Z.L.; resources, Z.L. and H.W.; data curation, Z.L. and Z.S.; writing-original draft preparation, Z.L.; writing—review and editing, Z.L.; visualization, Z.L.; supervision, Z.L.; project administration, Z.L.; funding acquisition, Z.L. and Y.F.

Funding: This research was funded by Tiandi Science and Technology Co., Ltd. Science and Technology Innovation Venture Capital Special Project, grant numbers "2019-TD-QN005 and 2018-TD-QN025", National Natural Science Foundation of China, grant number "No. 5177041222", National Key Research and Development Program of China, grant number "No. 2017YFC0804205".

Acknowledgments: This paper was supported by Tiandi Science and Technology Co., Ltd. Science and Technology Innovation Venture Capital Special Project (2019-TD-QN005, 2018-TD-QN025), National Natural Science Foundation of China (No. 5177041222), National Key Research and Development Program of China (No. 2017YFC0804205). The authors would like to acknowledge anonymous reviewers for their valuable comments and suggestions.

Conflicts of Interest: The authors declare no conflict of interest.

\section{References}

1. Brodny, J.; Tutak, M. Analysing the Utilisation Effectiveness of Mining Machines Using Independent Data Acquisition Systems: A case study. Energies 2019, 12, 2505. [CrossRef]

2. Brodny, J.; Tutak, M. Exposure to Harmful Dusts on Fully Powered Longwall Coal Mines in Poland. Int. J. Environ. Res. Public Health 2018, 15, 1846. [CrossRef] [PubMed]

3. Yan, P.; Zhao, Z.; Lu, W.; Fan, Y.; Chen, X.; Shan, Z. Mitigation of rock burst events by blasting techniques during deep-tunnel excavation. Eng. Geol. 2015, 188, 126-136. [CrossRef]

4. Zhang, C.; Canbulat, I.; Hebblewhite, B.; Ward, C.R. Assessing coal burst phenomena in mining and insights into directions for future research. Int. J. Coal Geol. 2017, 179, 28-44. [CrossRef]

5. Zhao, G.; Wang, D.; Gao, B.; Wang, S. Modifying rock burst criteria based on observations in a division tunnel. Eng. Geol. 2017, 216, 153-160. [CrossRef]

6. Turchaninov, I.A.; Markov, G.A.; Gzovsky, M.V.; Kazikayev, D.M.; Frenze, U.K.; Batugin, S.A.; Chabdarova, U.I. State of stress in the upper part of the earth's crust based on direct measurements in mines and on tectonophysical and seismological studies. Phys. Earth Planet. Inter. 1972, 6, 229-234. [CrossRef] 
7. Russenes, B.F. Analysis of Rock Spalling for Tunnels in Steep Valley Sides; Department of Geology, Norwegian Institute of Technology: Trondheim, Norway, 1974.

8. Hoek, E.; Brown, E. Practical estimates of rock mass strength. Int. J. Rock Mech. Min. Sci. Géoméch. Abstr. 1997, 34, 1165-1186. [CrossRef]

9. Su, G.S.; Shi, Y.J.; Feng, X.T.; Jiang, J.Q.; Zhang, J.; Jiang, Q. True-triaxial experimental study of the evolutionary features of the acoustic emissions and sounds of rockburst processes. Rock Mech. Rock Eng. 2018, 51, 375-389. [CrossRef]

10. Zhao, Y.X.; Jiang, Y.D. Acoustic emission and thermal infrared precursors associated with bump-prone coal failure. Int. J. Coal Geol. 2010, 83, 11-20. [CrossRef]

11. Zhao, Y.X.; Jiang, Y.D.; Tian, S.P. Investigation on the characteristics of energy dissipation in the preparation process of coal bumps. J. China Coal Soc. 2010, 35, 1979-1983.

12. Li, Z.L.; Dou, L.M.; Cai, W.; Wang, G.F.; Ding, Y.L.; Kong, Y. Roadway stagger layout for effective control of gob-side rock bursts in the longwall mining of a thick coal seam. Rock Mech. Rock Eng. 2016, 49, 621-629. [CrossRef]

13. Li, Z.; Dou, L.; Cai, W.; Wang, G.; He, J.; Gong, S.; Ding, Y. Investigation and analysis of the rock burst mechanism induced within fault-pillars. Int. J. Rock Mech. Min. Sci. 2014, 70, 192-200. [CrossRef]

14. Hua, A.-Z.; You, M.-Q. Rock failure due to energy release during unloading and application to underground rock burst control. Tunn. Undergr. Space Technol. 2001, 16, 241-246. [CrossRef]

15. Mansurov, V.A. Prediction of rockbursts by analysis of induced seismicity data. Int. J. Rock Mech. Min. Sci. 2001, 38, 893-901. [CrossRef]

16. Sun, J.-S.; Zhu, Q.-H.; Lu, W.-B. Numerical Simulation of Rock Burst in Circular Tunnels Under Unloading Conditions. J. China Univ. Min. Technol. 2007, 17, 552-556. [CrossRef]

17. Wang, J.A.; Park, H.D. Comprehensive prediction of rockburst based on analysis of strain energy in rocks. Tunn. Undergr. Space Technol. 2001, 16, 49-57. [CrossRef]

18. Cook, N. The design of underground excavations. American Rock Mechanics Association. In American Rock Mechanics Association. In Proceedings of the 8th US Symposium on Rock Mechanics (USRMS), Minneapolis, MN, USA, 15-17 September 1966.

19. Neyman, B.; Szecowka, Z.; Zuberek, W. Effective methods for fighting rock burst in Polish collieries. In Proceedings of the 5th International Strata Control Conference, London, UK, September 1972.

20. Kidybiński, A. Bursting liability indices of coal. Int. J. Rock Mech. Min. Sci. Geomech. Abstr. 1981, 18, $295-304$. [CrossRef]

21. Singh, S.P. Burst energy release index. Rock Mech. Rock Eng. 1988, 21, 149-155. [CrossRef]

22. Weng, L.; Huang, L.; Taheri, A.; Li, X. Rockburst characteristics and numerical simulation based on a strain energy density index: A case study of a roadway in Linglong gold mine, China. Tunn. Undergr. Space Technol. 2017, 69, 223-232. [CrossRef]

23. Beck, D.A.; Brady, B. Evaluation and application of controlling parameters for seismic events in hard-rock mines. Int. J. Rock Mech. Min. Sci. 2002, 39, 633-642. [CrossRef]

24. Jiang, Q.; Feng, X.-T.; Xiang, T.-B.; Su, G.-S. Rockburst characteristics and numerical simulation based on a new energy index: a case study of a tunnel at 2,500 m depth. Bull. Int. Assoc. Eng. Geol. 2010, 69, 381-388. [CrossRef]

25. Xu, J.; Jiang, J.; Xu, N.; Liu, Q.; Gao, Y. A new energy index for evaluating the tendency of rockburst and its engineering application. Eng. Geol. 2017, 230, 46-54. [CrossRef]

26. Zhang, X.Y.; Feng, G.R.; Kang, L.X.; Yang, S.S. Method to determine burst tendency of coal rock by residual energy emission speed. J. China Coal Soci. 2009, 9, 1165-1168.

27. Miao, S.J.; Cai, M.F.; Guo, Q.F.; Huang, Z.J. Rock burst prediction based on in-situ stress and energy accumulation theory. Int. J. Rock Mech. Min. Sci. 2016, 83, 86-94. [CrossRef]

28. Zhang, C.; Canbulat, I.; Tahmasebinia, F.; Hebblewhite, B. Assessment of energy release mechanisms contributing to coal burst. Int. J. Min. Sci. Technol. 2017, 27, 43-47. [CrossRef]

29. Zhang, C.; Tahmasebinia, F.; Canbulat, I.; Vardar, O.; Saydam, S. Analytical Determination of Energy Release in a Coal Mass. Energies 2018, 11, 285. [CrossRef]

30. Yang, X.; Ren, T.; Remennikov, A.; He, X.; Tan, L. Analysis of Energy Accumulation and Dissipation of Coal Bursts. Energies 2018, 11, 1816. [CrossRef]

31. Zheng, Z.S. Energy transfer process during rock deformation. Sci. China Ser. B 1991, 1, 104-117. 
32. Lin, P.; Liu, H.; Zhou, W. Experimental study on failure behaviour of deep tunnels under high in-situ stresses. Tunn. Undergr. Space Technol. 2015, 46, 28-45. [CrossRef]

33. Munoz, H.; Taheri, A.; Chanda, E.K. Pre-Peak and Post-Peak Rock Strain Characteristics During Uniaxial Compression by 3D Digital Image Correlation. Rock Mech. Rock Eng. 2016, 49, 2541-2554. [CrossRef]

34. Yamada, I.; Masuda, K.; Mizutani, H. Electromagnetic and acoustic emission associated with rock fracture. Phys. Earth Planet. Inter. 1989, 57, 157-168. [CrossRef]

35. Xie, H.P.; Ju, Y.; Li, L.Y. Criteria for strength and structural failure of rocks based on energy dissipation and energy release principles. Chin. J. Rock Mech. Eng. 2005, 24, 3003-3010.

36. Pan, Y.S.; Geng, L.; Li, Z.H. Research on evaluation indices for impact tendency and danger of coal seam. J. China Coal Soc. 2010, 12, 1975-1978.

37. Paterson, M.S.; Wong, T.F. Experimental Rock Deformation-The Brittle Field; Springer Science \& Business Media: Berlin, Germany, 2005.

38. Tarasov, B.; Potvin, Y. Universal criteria for rock brittleness estimation under triaxial compression. Int. J. Rock Mech. Min. Sci. 2013, 59, 57-69. [CrossRef]

(C) 2019 by the authors. Licensee MDPI, Basel, Switzerland. This article is an open access article distributed under the terms and conditions of the Creative Commons Attribution (CC BY) license (http://creativecommons.org/licenses/by/4.0/). 